\title{
La generación de valor entre las personas y las organizaciones
}

\section{Generating value between people and organizations}

\author{
Dagoberto Torres-Flórez
}

Cómo citar este artículo / Toreference this article:

Torres-Flórez, D. (2020). La generación de valor entre las personas y las organizaciones. Revista GEON (Gestión, Organizaciones Y Negocios), 7(1), 4-8. https://doi. org/10.22579/23463910.211

Esta publicación se encuentra bajo licencia:

Creative Commons ReconocimientoNoComercialSinObraDerivada 4.0 Internacional

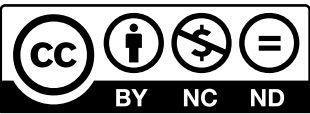

\section{Resumen Editorial}

La labor de gestión humana es lograr la generación de valor en las organizaciones, para ello debe aportar en la mediación entre la dirección y los colaboradores, es necesario que cada uno haga su parte, pues debe ser un trabajo en equipo con sinergia la que logrará contribuir a la consecución de metas organizacionales que todos los grupos de interés caminen hacia los mismos objetivos permitiendo un desarrollo organizacional efectivo.

Palabras clave: talento humano, generación de valor, desarrollo organizacional, calidad laboral, ambiente saludable, personas idóneas, aspectos organizacionales, ayudar a crecer.

\section{Abstract}

The work of human management is to achieve the generation of value in organizations, for this it must contribute to mediation between management and collaborators, it is necessary that each do their part, since it must be a teamwork with synergy that achieves contribute to the achievement of organizational goals so that all interest groups walk towards the same specific objectives, effective organizational development.

Key words: human talent, value generation, organizational development, job quality, healthy environment, suitable people, organizational aspects, helping to grow.

1 Phd (c) Ciencias Económicas y administrativas, Colombia, Universidad de los Llanos, Editor Revista GEON, Líder grupo de investigación GYDO, dtorres@ unillanos.edu.co@dagoto https://orcid.org/0000-0002-7925-3005 


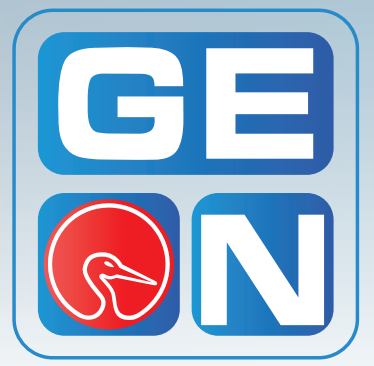

\section{Revista GEON}

(Gestión, Organizaciones y Negocios)

ISSN: 2346-3910 en línea

revistageon@unillanos.edu.co

Universidad de los Llanos

Colombia

\section{Dagoberto Torres-Flórez (2020).}

La generación de valor entre las personas

y las organizaciones

Revista GEON

(Gestión, Organizaciones y Negocios), 7(1), 4-8.

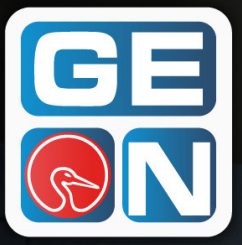

\section{Revista GEON \\ $f$ in 90}

66 La labor de gestión humana es lograr la generación de valor en las organizaciones, para ello debe aportar en la mediación entre la dirección y los Colaboradores.

es necesario que cada uno haga su parte, pues debe ser un trabajo en equipo con sinergia

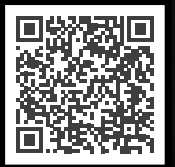

Torres-Flórez, D. (2020). La generación de valor entre las personas y las organizaciones. Revista GEON (Gestión, Organizaciones Y Negocios), 7(1), 4-8.

http://revistageon.unillanos.edu.co 


\section{Introducción.}

En la vida las personas se enfrentan cada día a situaciones de decisión algunas de menor complejidad como elegir que se desayuna o situaciones estructuradas como comprar una casa o un auto, pero son las características personales, de gustos y preferencias las que aportan a la toma de decisiones. En este ambiente de posibilidades es necesario que antes de tomar aquellas decisiones se tenga en cuenta el entorno, la información con la que cuenta la institución y como esta puede ayudar a visualizar con prospectiva los efectos de esas acciones.

Para estas situaciones es necesario que se cuente con acción de decisión y para ello se debe fomentar la iniciativa de manera eficaz entre los grupos de interés, que cuando se genere una idea se logre materializar con planeación, estrategia, dirección con el fin de hacer que las cosas suceden, probablemente en muchas ocasiones las personas se quedan en las ideas, pero no realizan acciones que permitan lograr que esas ideas se vuelvan realidad (Torres-Flórez, 2016).

\section{Desarrollo.}

Es relevante comprender la relación entre las personas y las organizaciones, para ello se destaca desde tres enfoques el de la dirección; gestión humana; y las personas que hacen parte de ella.

Enfoque de la Dirección. En las organizaciones existen personas que por sus roles o cargos deben dirigir u supervisar a otros, para ello es necesario desarrollar o adquirir tres competen- cias claves que le permitan generar valor a los actos que realice, para esto es necesario que tenga capacidad de motivar, liderar y comunicar.

Respecto al motivar en ello se plantea una reflexión, debido a que no se pueden obligar a las personas a motivarse, pues para que una persona se sienta así, le debe surgir de adentro del ser, por ello es necesario algunos elementos para motivar cómo un buen clima organizacional, las características de las personas, las generaciones en cuestiones de edad, los gustos, preferencias, es relevante conocer al colaborador no solo en su desempeño sino en sus cuestiones personales que permitan identificar aquellas cosas que podrían aportarle valor al colaborador, para que su sentir de motivación fluya de manera adecuada. Pues una persona motivada lo refleja en su actuar, en su sentir, en sus expresiones lo transmite a los demás y esto es lo que se debe buscar.

Hoy en día es muy común hablar de liderazgo el cual se enfocamos a transacciones a lograr dar instrucciones y que sean realizadas, a influir en otras personas para que se lleguen a objetivos comunes y está bien plantearlo así, sin embargo, se debe ir más allá, es la capacidad de inspirar a otros, de con su ejemplo o testimonio logre transformar no solo las cuestiones profesionales o laborales, sino también las personales.

Otra competencia que debe desarrollar el gerente o administrador es lograr aprender a comunicar, que la información fluya dentro de la organización sin ruido, que se comprenda, que sea un mensaje claro, sencillo, 
que se entienda su contexto, conocer quién es el público a quien va dirigido, utilizar los canales adecuados para que logre ser eficaz y eficiente en el avance organizacional, pero no solo en forma escrita, sino también como se expresan las personas de manera corporal o gestual.

Este enfoque busca entregar al gerente o administrador competencias para poder tomar decisiones, resolver problemas y solucionar conflictos.

Enfoque de gestión humana. Respecto a las practicas que deben tener las organizaciones en cuanto a la gestión de sus colaboradores, todo nace en contar con unos aspectos organizacionales definidos y estructurados, como un manual de descripción y análisis de puestos organizado, acorde a las necesidades, procedimientos y procesos mínimos para que las personas desarrollen bien sus tareas, luego realizar acciones para encontrar personas idóneas con unas prácticas de reclutamiento y selección adecuadas que logren encontrar esa persona que realmente llegue a contribuir a la organización (Torres-Flórez, 2018b).

También es necesario que cuando ya se cuente con los colaboradores idóneos, se desarrollen prácticas que permitan ayudar a crecer a las personas y a la organización, como el entrenamiento basado en la inducción y la capacitación (Torres-Flórez, 2019a), gestionar el desempeño para poder encontrar en forma continua acciones de mejora tanto individuales como grupales en pro del avance y crecimiento empresarial (Torres-Flórez, 2018a).
Para esto es primordial contar con una calidad laboral, respecto al establecer salarios justos, pagar puntualmente, contratos que beneficien a las partes, programas de bienestar laboral, brindar acceso al sistema de seguridad social, aumentos e incentivos que sean acordes al desempeño, pero sobre todo generar unos aspectos laborales mínimos que produzcan bienestar en el colaborador (Torres-Flórez, 2019b).

Al igual se busca que el colaborador cuente con un ambiente saludable que se le brinde las estrategias necesarias para mantener un buen estado de salud y seguridad en su puesto de trabajo, con elementos de protección individual adecuados que protejan el estado del colaborador, exámenes médicos que permitan valorar las condiciones en forma periódica, diseñar estrategias para identificar, valorar y mitigar los factores de riesgo que puedan afectar el desarrollo individual y de la organización.

Enfoque de las personas. En este elemento lo que se plantea es que cada miembro es en sí parte de la organización, pero para ello la empresa debe lograr desarrollar en ellas conocimientos, habilidades y actitudes en un justo equilibrio, para esto se podría tomar la referencia que plantea Kuppers (2013) con su fórmula de valor, donde los conocimientos suman, las habilidades suman, pero las actitudes multiplican, pues las personas son grandiosas y se recuerdan por su manera de ser.

A esto es importante reflexionar que las personas podrían adquirir conocimientos y habilidades en algunos 
días o semanas, pero modificar sus actitudes o comportamientos podría suceder, pero para ello requiere tiempo, pues enseñarle Excel a alguien lo podría aprender en semanas, pero encontrar a alguien con algún antivalor y pedirle que lo modifique de la noche a la mañana se vuelve complicado, pues requiere modificar el comportamiento.

\section{Conclusiones.}

Es importante que gestión humana logre ser aquella mediadora para que los colaboradores sean socios estratégicos y la organización le genere a sus colaboradores calidad de vida y así le aporte valor a la organización.

Otro reto que cuenta la organización es lograr que la persona alinee sus objetivos individuales con los organizacionales, pues si la persona y la empresa caminan hacia el mismo lado podrán crecer de manera más rápida.

Es necesario que las organizaciones reconozcan como el capital humano le está generando valor y que es este el que ayuda en forma directa en la consecución de metas, pues son las personas la nueva ventaja competitiva de las organizaciones.

Las personas dedican gran parte de su tiempo a las organizaciones por ello debemos generar espacios saludables y agradables, cada vez se depende más de acciones grupales que individuales y que las metas solo se consiguen con un trabajo en sinergia.

Al igual tratar a las personas como tal, con humanización, ayudarlas a crecer no solo manera profesional sino perso- nalmente, formarlo, ser justos con las compensaciones, que sean claras para el colaborador y siempre buscando la motivación, el estilo de la dirección influirá en el desarrollo organizacional, con un colaborador comprometido y motivado se crecerá en forma dinámica y no olvidar que se trabaja con personas y no solo con máquinas.

\section{Referencias.}

Kuppers, V. (2013). Tu estado de ánimo es tu responsabilidad. Indicador d'Economia, 28. Obtenido de http:// www.kuppers.com/1/upload/2_la_ contra_indicador_de_economii_a.pdf

Torres-Flórez, D. (2018a). La importancia de la gestión del desempeño en las organizaciones. Revista GEON (Gestión, Organizaciones Y Negocios), 5(1), 4-5. https://doi.org/10.22579/23463910.2

Torres-Flórez, D. (2018b). Siete pasos para hacer una selección de personal que le aporte valor a la organización. Revista GEON (Gestión, Organizaciones Y Negocios), 5(2), 4-7. https://doi. org/10.22579/23463910.80

Torres-Flórez, D. (2016). La responsabilidad social empresarial, más allá de lo legal. Revista GEON (Gestión, Organizaciones Y Negocios), 3(1), 4. https:// doi.org/10.22579/23463910.66

Torres-Flórez, D. (2019a). El entrenamiento del colaborador como estrategia de mejoramiento continuo. Revista GEON (Gestión, Organizaciones Y Negocios), 6(1), 4-9. https://doi. org/10.22579/23463910.149

Torres-Flórez, D. (2019b). Estrategia de compensaciones como herramienta de satisfacción laboral. Revista GEON (Gestión, Organizaciones Y Negocios), 6(2), 4-9. https://doi. org/10.22579/23463910.181 